\title{
THE PATELLO-FEMORAL JOINT Methods of Diagnosis: Clinical Disorders and Their Treatment
}

A. Graham Apley, F.R.C.S.

Consultant Orthopaedic Surgeon, Rowley Bristow Orthopaedic Hospital, Pyrford

The knee has two joints, the tibio-femoral and the patello-femoral, but until recent years the second has received relatively little attention. This neglect is surprising, because the importance of lesions of the extensor mechanism, and the need for a powerful quadriceps muscle, have long been appreciated. This article surveys first the methods of examination of the patello-femoral joint, then its disorders, and finally the operation of patellectomy. The disorders are in two main groups: displacements (subluxation and dislocation) and degenerations (chondromalacia and osteoarthritis). All these conditions are linked, for recurrent dislocation and subluxation are potent causes of chondromalacia which, in turn, is a forerunner of osteoarthritis.

\section{Examination of the Patello-Femoral Joint}

With derangement of the knee it is not sufficient to examine only the tibio-femoral joint; the patello-femoral joint also must be examined in every case. The patient lies on a couch with both lower limbs exposed. A fixed routine of examination should, as always, be employed; first we look, then feel, then move the joint, and finally examine $\mathrm{X}$-ray films.

Look. The skin is inspected for scars, and the shape of the limb observed for valgus or varus deformity. Wasting of the thigh and swelling in the supra-patellar pouch are easily seen. Finally, we look at the patella itself to see if it is normal in position, size and shape.

Feel. The skin is palpated for increased warmth and the supra-patellar pouch for excess fluid. When palpating for tenderness, it is important not only to feel the margins of the patella, but also to push it laterally with one hand, while the fingers of the other feel the lateral portion of its posterior surface (Fig. I).

Move. Extension, flexion and rotation of the knee are tested, but these are mainly concerned with tibio-femoral disorders. Two special tests involving patello-femoral movement are important. I have used them for a number of years and found them consistently helpful.

\section{The Apprehension Test}

With one hand the patella is pushed laterallyw while the other hand flexes the knee. If the patient has recurrent dislocation or subluxation excess lateral mobility can sometimes be demon strated. The essence of the test is, howevero that as flexion proceeds the patient is usually seent to wince. The term ' apprehension test' seems appropriate because the patient, not unreasonablyo is apprehensive lest the displacement be repro duced during the test (Fig. 2).

\section{The Patellar Friction Test}

With the knee straight the patella is moved up and down, then from side to side; during these movements it should be firmly pressed against th⿻ 丨丨 femur (Fig. 3). The diagnostic feature is that grating sensation may be felt, or pain elicited? the articular cartilage on the back of the patella is irregular, as in chondromalacia or osteoarthritiso

\section{$X-r a y$}

Standard antero-posterior and lateral view of the knee are not enough, and a special projec $\exists$ tion is necessary; this is known as the patello femoral, tangential or sky-line view (Fig. 4). I this view the width of the joint space between the patella and the lateral femoral condyle may be. seen to be diminished, the posterior surface of the patella may be irregular, or osteophytes may b visible.

\section{Recurrent Dislocation of the Patella Causes}

I. Muscle Weakness

The patella may be dislocated by a single majo心 injury. Unless, after reduction, the quadricepss muscle is redeveloped to its full power, dislocatio may recur, because wasting of the quadriceps if usually most marked in the vastus medialis, 8 muscle which helps prevent lateral shift of the patella.

\section{Anatomical Abnormalities}

With genu valgum the patella is more likely 


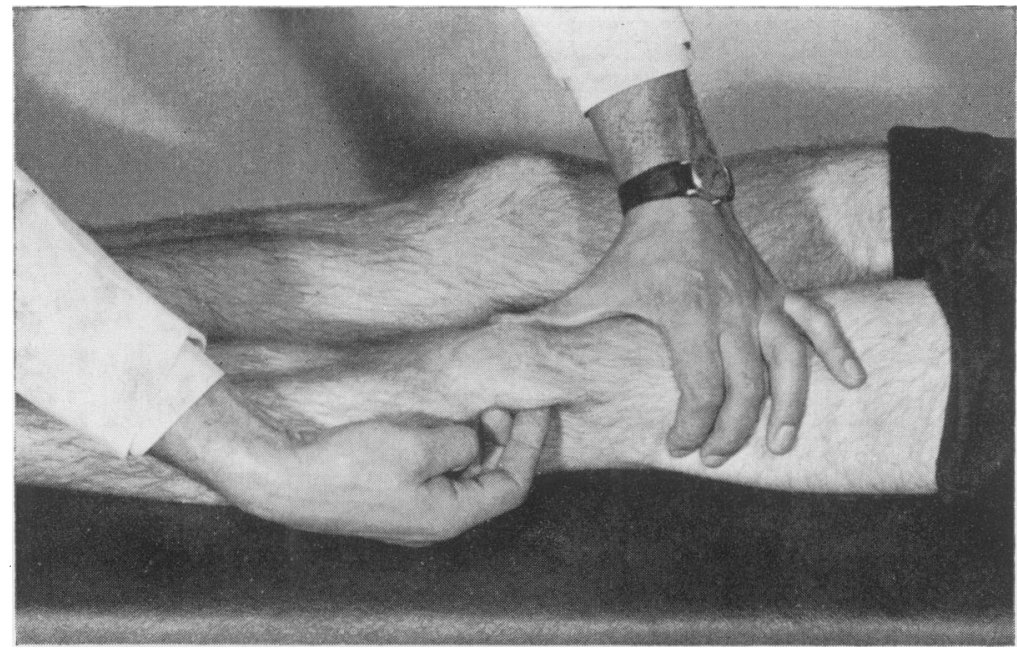

Fig. I.-Feeling the back of the lateral aspect of the patella for tenderness.

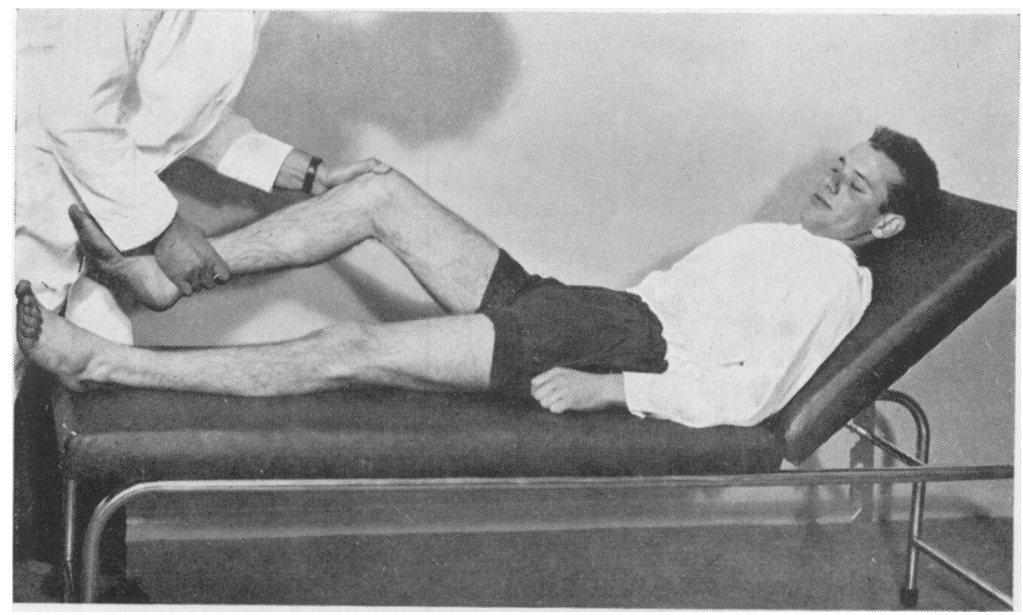

Fig. 2. - The apprehension test is strongly positive with recurrent dislocation of the patella and often positive with recurrent subluxation.

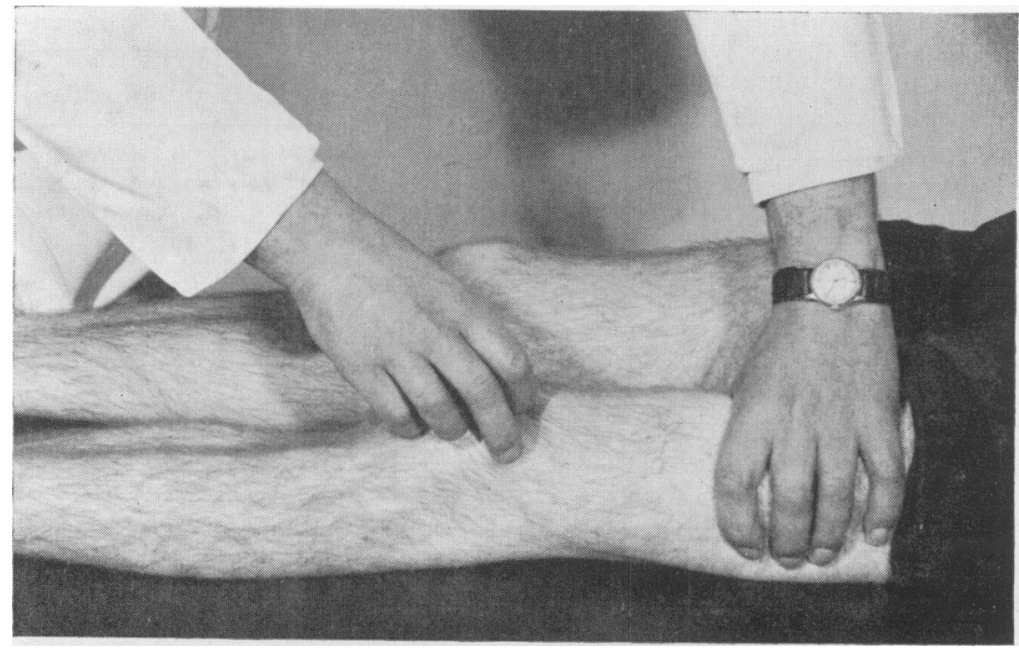

Fig. 3.-The.patellar friction test is positive whenever the back of the patella is rough. 


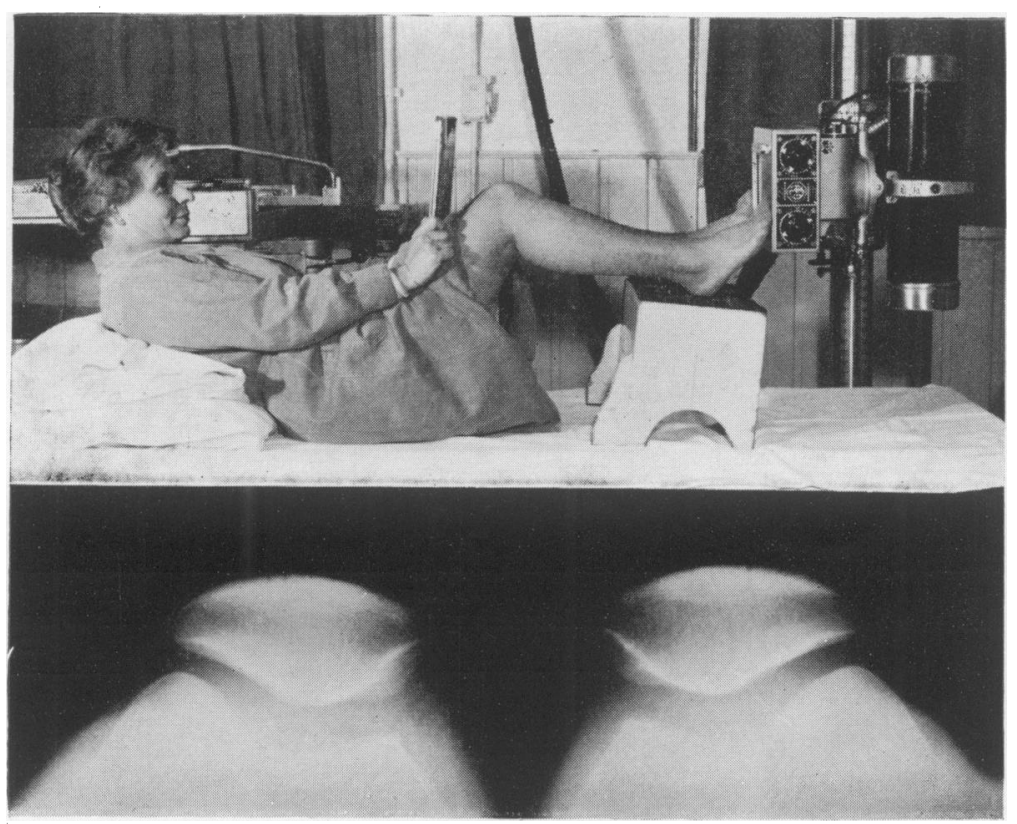

dislocate because the line of pull of the quadriceps when the knee is valgus tends to displace the patella laterally.

With normal muscle dislocation of the patella is prevented by contact with the ridge on the lateral femoral condyle. This checking mechanism fails if the ridge is poorly developed, if the patella is too small or too high, or if the knee normally extends beyond $180 \mathrm{deg}$.

It should be emphasized that the majority of patients with recurrent dislocation of the patella have no gross abnormality and the cause of the dislocation is not obvious.

\section{Pathology}

Dislocation is always to the lateral side. The capsule on the medial side of the patella is torn and, if it fails to unite properly, lateral laxity persists. Repeated dislocation damages the contiguous surfaces of patella and femoral condyle; degenerative changes follow which may result in flattening of the condyle, so facilitating further dislocations.

\section{Symptoms}

The patient complains of attacks during which the knee suddenly gives way, moves out of position, and may get stuck. As the patella displaces to the lateral side of the lateral femoral condyle the patient may be thrown to the ground. If the patella remains in this position the knee is stuck in acute flexion. This history is much more dramatic than that of locking due to a torn meniscus, with which the lesion was formerlo $\vec{\theta}$ confused.

As a rule the patella spontaneously slips baes to its normal position; sometimes it is reduce by the patient or a bystander, and occasionally the patient is brought to hospital with the patella still dislocated. The first dislocation may have followed a definite injury; subsequent attacks occur while walking, running or cycling, and tend to come out of the blue without warning. Between attacks, the knee seems normal.

\section{Signs}

\begin{tabular}{|c|c|}
\hline Recur & Torn Medial Meniscus \\
\hline $\begin{array}{l}\text { More common in females } \\
\text { Knee locks acutely flexed } \\
\text { Patient thrown to the } \\
\text { ground } \\
\text { Tender above joint line } \\
\text { Apprehension test positive } \\
\text { Rotation painless }\end{array}$ & $\begin{array}{l}\text { More common in males } \\
\text { Knee locks slightly flexed } \\
\text { Patient sinks to the } \\
\text { ground } \\
\text { Tender on the joint line } \\
\text { Apprehension test nega- } \\
\text { tive } \\
\text { Rotation painful }\end{array}$ \\
\hline
\end{tabular}

Girls in their late teens are the chief sufferers, though boys are sometimes affected and the condition may occur in young adults. Sometimes it is bilateral.

The appearance of the dislocated knee is unmistakable. The joint is held flexed, the patella is on the lateral side of the knee facing outwards, 
and the uncovered medial femoral condyle constitutes an abnormal prominence. This prominence on the inner side is so obvious that the patient may mistakenly suppose that the patella has displaced medially. Between attacks the signs are as follows:

Look: The knee may be valgus or the quadriceps wasted, but usually the appearance is normal.

Feel: The patella may be too small or too high and, for a few days after an attack, there is tenderness medial to the patella where the capsule has been torn. If dislocation has been repeated the lateral portion of the posterior surface of the patella may be tender.

Move: Flexion and extension of the knee may be full and painless and rotation may be normal, but the patella is unduly mobile laterally and the apprehension test is strongly positive. This test is reliable and almost invariably diagnostic. After repeated attacks the patellar friction test also becomes positive, indicating that articular cartilage degeneration has occurred.

$X$-ray: It is necessary to exclude a loose body, but in most cases the $\mathrm{X}$-ray appearance is normal.

\section{Treatment}

The first time a patella dislocates it must be reduced, the joint aspirated if necessary, and the knee splinted in the straight position. A plaster tube is applied from the groin to the malleoli, and the anterior third of this plaster is removed so that a firm backslab remains. On the next day the patient is taught quadriceps exercises. As soon as she can easily lift her leg she is allowed up and taking weight. Walking is encouraged, and repeated muscle exercises insisted upon. The back slab is removed for daily exercises; after six weeks it is discarded and knee movements regained by active exercise.

If dislocation has become recurrent operative treatment is essential, for the patient is liable to fall while crossing a road or walking down stairs. Formerly, a number of different operations were in vogue such as elevation of the lateral femoral condyle (Albee), or reinforcement of the medial capsule with fascia (Gallie). These have now been abandoned; instead, the patella is either realigned more medially or is excised.

\section{Patellar Re-alignment}

This is indicated when only a few attacks have occurred and there is no evidence of chondromalacia patellae. A lateral para-patellar incision is used and is extended distally, inclining to the medial side and ending two inches below the tibial tubercle. The patellar ligament is defined

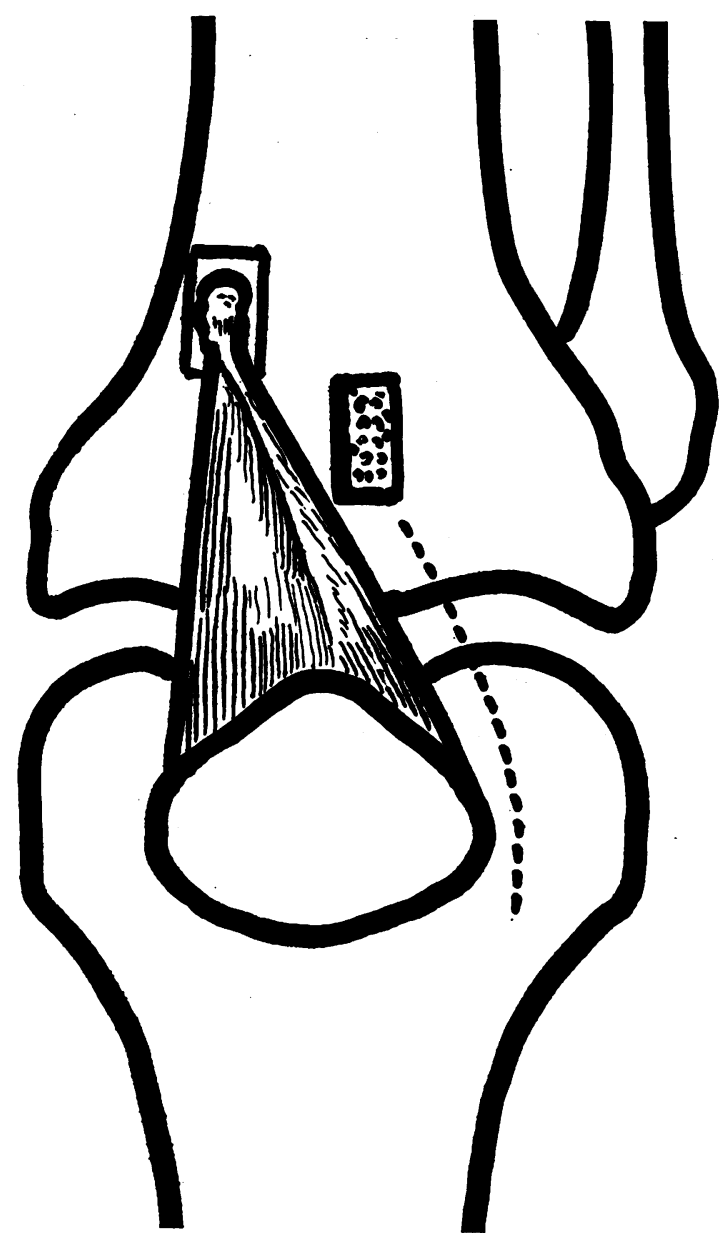

FIG. 5.-The insertion of the ligamentum patellae is transplanted distally and medially.

and detached together with a rectangular block of bone including its insertion. The capsule lateral to the patella is then divided in the line of the incision to allow the bone to be moved medially without tension. A cavity is prepared in the tibia, $\frac{3}{4}$-in. medial to and below the tibial tubercle. The block of bone bearing the patellar ligament is fitted into the cavity; it may either be latched securely in position or is fastened with sutures, staples or a screw (Fig. 5). The medial capsule is plicated, but the lateral capsule is left unsutured. A splint is worn for six weeks.

\section{Patellectomy}

This is indicated if degenerative changes have developed on the articular cartilage of the patella. If there have been several attacks such changes are inevitable even if clinically unrecognized at first and McFarland (1948) advocates patellectomy 
as the routine treatment. The technique of the operation is described later.

Each of the above operations is seen to have its own clear-cut indications; each also has its own special complication. Following re-alignment, chondromalacia, which was perhaps too early to have been recognized previously, may progress. Following patellectomy, the patellar tendon and ligament may dislocate in the same way as the patella, though this complication is rare. The treatment of advancing chondromalacia is patellectomy; the treatment of recurrent ligament dislocation is re-alignment. It is therefore seen that either of the two operations may occasionally need to be followed by the other.

\section{Recurrent Subluxation of the Patella}

The patient, usually a young girl, complains of repeated giving way of the knee, of momentary catches of pain, and sometimes of recurrent swelling. The patella moves laterally, teeters on the femoral condyle and instead of displacing completely it returns to its normal position. If the patient is asked to describe the very first time the knee gave trouble (a question which should never be omitted with any knee derangement) sometimes she may recall a complete dislocation.

The history is less dramatic than that of recurrent dislocation, but the condition is more common and is more often mis-diagnosed as a torn meniscus. The absence of the characteristic history and signs of a torn meniscus, together with a positive apprehension test, should enable an accurate diagnosis to be made. Chondromalacia eventually supervenes and the treatment is patellectomy.

\section{Chondromalacia Patellae Cause}

This important condition was first described in Scandinavia (Owre, 1935). The articular cartilage of the patella, which is normally much thicker than that of the femoral condyle, is very liable to be damaged by repeated minor falls on to the knee-cap or by a single major injury. The cartilage may also be damaged by recurrent subluxation or dislocation as already described.

\section{Pathology}

The articular cartilage loses its normal smooth glistening appearance. In one or more areas it becomes oedematous, dull and soft, so that at operation it is easily indented. Fine irregular cracks may be seen, together with small indentations or heaped-up nodular areas (Fig. 6). Sometimes a flat shallow cavity, devoid of the superficial layers of cartilage is seen, and occasionally a

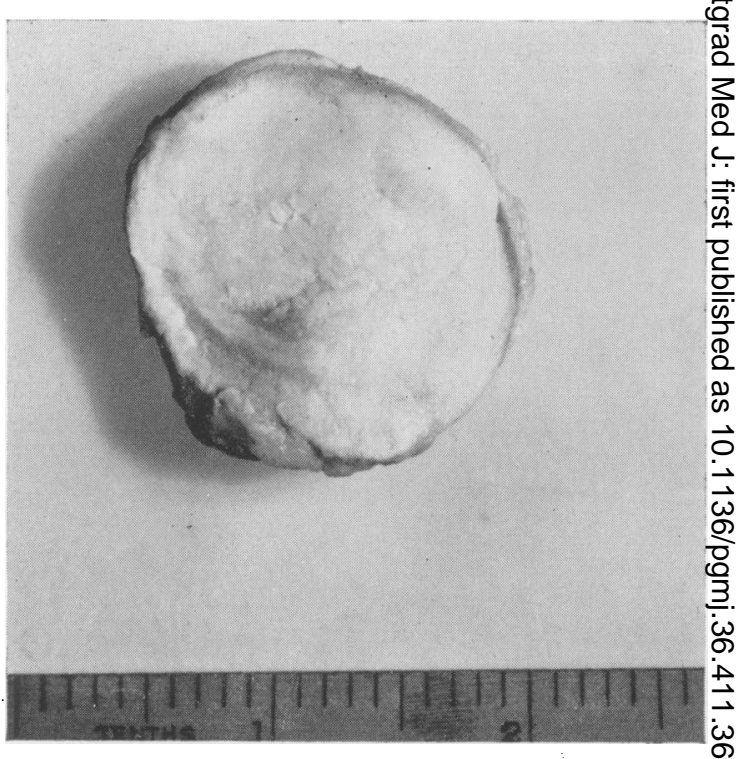

FIG. 6.-Chondromalacia: the articular cartilage is $\frac{\mathrm{O}}{\mathrm{C}}$ rough and irregular.

cauliflower-like excresence apparently erupting from a small cavity. Not uncommonly, a 'kissing lesion on the femoral condyle is found, opposide $\vec{\theta}$ the affected area of the patella.

\section{Symptoms}

The patient complains of pain, giving way and recurrent swelling. Characteristically the pain is worse on stairs, especially going downstairs. The $\frac{}{\Phi}$ giving way is sometimes described as locking, but $\stackrel{2}{\vec{F}}$ is more in the nature of an interruption in the $\frac{3}{3}$ normal smooth movement of knee flexion. Gray (1948) used the phrase 'semi-locking,' a useful and descriptive term. True locking does not occur unless a loose body separates, which is 3 . uncommon.

\section{Signs}

Young adults are affected, especially females.

Look: The appearance is normal unless there has been a recent effusion.

Feel: Tenderness can often be elicited, especially on the postero-lateral aspect of the patella when it is pushed laterally, and at the lower pole.

Move: The patellar friction test is positive so స్ట that as the patella is pushed against the femur and 0 moved, grating and pain occur. Flexion and extension are usually normal.

$X$-ray: At first the X-ray appearance may be $\stackrel{\oplus}{+}$ normal, but if the skyline view is of high quality 0 fine lines may be seen running forwards from the 0 back of the patella (Fig. 7). Later patello-femoral 


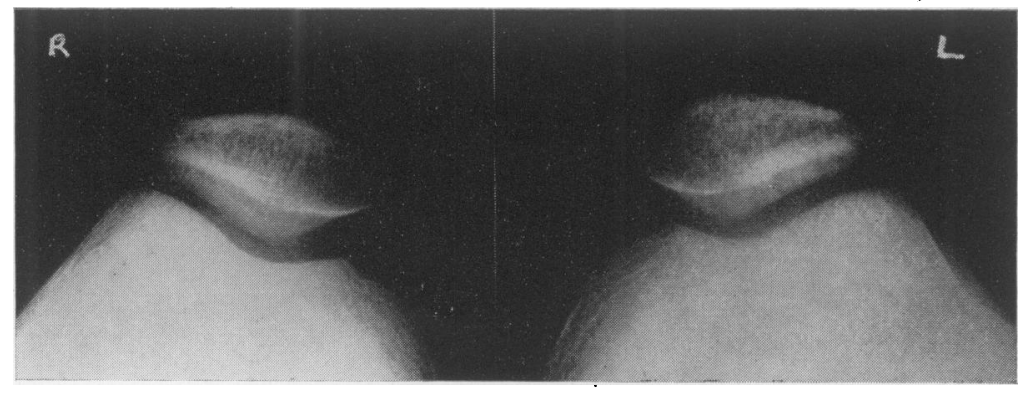

osteoarthritis supervenes; the skyline view then shows narrowing of the space between the patella and the lateral femoral condyle (Fig. 8).

\section{Treatment}

The only really effective treatment is patellectomy, but as a rule this is contra-indicated because attacks are infrequent and symptoms slight. It might be reasonable to advocate operation even in mild cases if we were sure that chondromalacia invariably progressed to osteoarthritis. Often, however, the symptoms abate and they may disappear completely. This is somewhat surprising with a degenerative lesion of an avascular structure such as articular cartilage, in which healing would not be expected to occur.

In mild cases, therefore, conservative treatment is advised. A course of short-wave diathermy is given and if symptoms persist the knee is manipulated under anaesthesia. The knee is flexed, extended and rotated, then the patella is moved fully in each direction; nowadays it is customary also to inject a mixture of local anaesthetic and hydrocortisone. In more severe cases operation is advisable. Some surgeons have advocated excising the affected area of cartilage (Karlson, I939), others shaving away the surface layers until the cartilage is smooth (Slowick, 1935). In England, patellectomy has almost completely superseded these procedures.

\section{Patello-Femoral Osteoarthritis}

Osteoarthritis is much more common in the patello-femoral joint than in the tibio-femoral joint. It may follow an injury, chondromalacia, recurrent dislocation or subluxation. A less common cause is splitting osteochondritis; in this disorder, which only rarely affects the patella, a segment of cartilage and bone separates off the back of the patella, leaving an irregular crater.

In osteoarthritis the articular cartilage is thinned and small pieces ('detritus') flake off. The patello-femoral joint space diminishes and osteo-

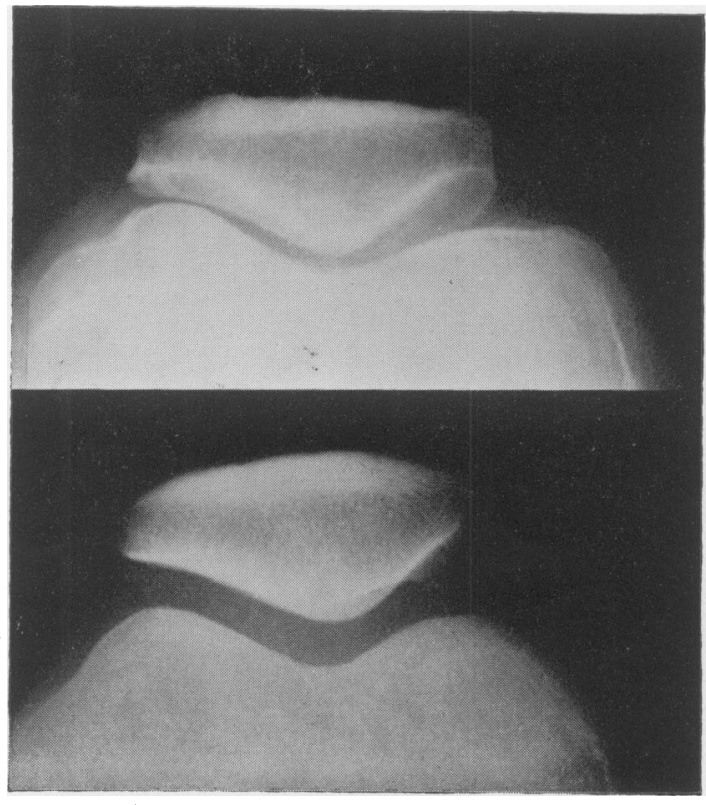

FIG. 8.-Early patello-femoral osteoarthritis is best seen in the skyline view; a normal knee is shown for comparison.

phytes form, especially at the outer and upper edges of the patella.

The clinical features resemble those of chondromalacia, but in a more obvious and exaggerated form. The patient complains of catches of pain, especially on stairs, and later of a more constant ache. Recurrent effusion is common. The joint may be swollen and the patellar edges tender. The patellar friction test is strongly positive. $\mathrm{X}$-ray films show the diminished patello-femoral space, the osteophytes, and often some irregularity of the posterior surface of the patella (Fig. 9).

Conservative treatment is rarely effective, though heat or manipulation may be temporary palliatives. Patellectomy is indicated if the symptoms warrant. Operation should, when 


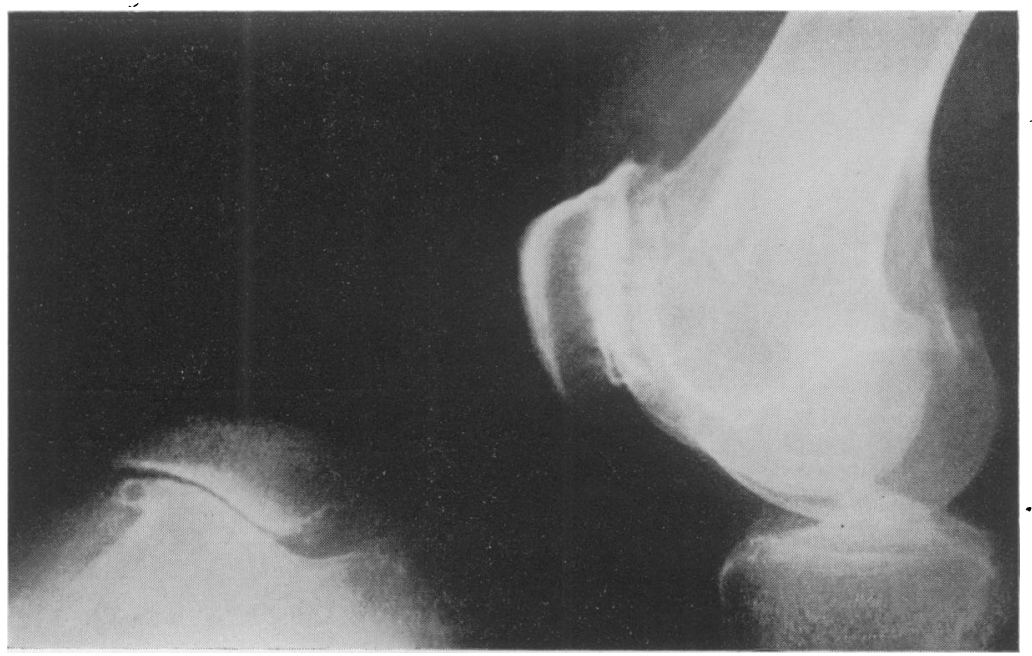

Fig. 9.-Advanced patello-femoral osteoarthritis.

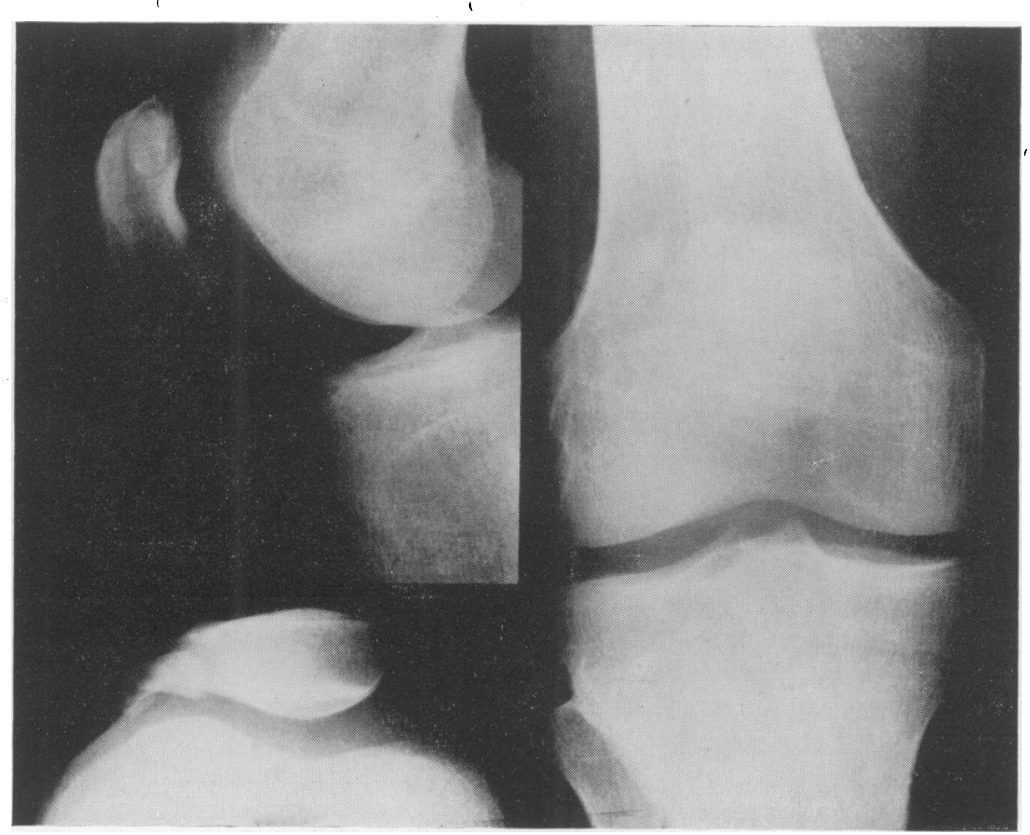

FIG. I0.-A bipartite patella is sometimes difficult to recognize in the anteroposterior view, but is easily seen in the skyline view.

possible, be performed before the development of osteoarthritic changes in the tibio-femoral joint, to which patello-femoral osteoarthritis is a precursor. French (1959) has indeed advocated that in any patient with recurrent effusion the knee should be explored so that early degenerative changes can be recognized.

\section{The Bipartite Patella}

With the rare bipartite patella X-ray of the knee shows a broad line across the supero-lateral angle of the patella. The condition is thought to beo congenital in origin, a view which is to some extentw supported by the fact that both patellae may be affected. Even when the appearance is firste noticed immediately after an injury, it may bed postulated that the X-ray appearance is unrelated

and of no importance (Fig. IO).
It seems possible, however, that a bipartite $e^{\frac{0}{0}}$

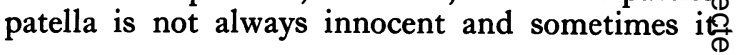


may produce patello-femoral symptoms and signs. The patient presents with symptoms resembling those of chondromalacia. The ' crack' may be palpable on its anterior surface, the superolateral angle of the back of the patella may be tender and the patellar friction test is usually positive. In the few cases in which symptoms have merited operation I have found a 'step' between the two portions of the patella, and through a short incision have removed the smaller supero-lateral portion. This limited procedure appears to have relieved the symptoms completely.

\section{Patellectomy}

A knee without a patella can be, in all other respects, a normal knee (Brooke, I937). In the preceding pages various indications for patellectomy have been described; the operation is also indicated in transverse gap fractures of the patella and in those stellate fractures where the posterior surface of the bone is irregular. It must be emphasized that an essential feature of the operation is repair of the extensor mechanism. Unless the patellar tendon and ligament are firmly joined together, active knee extension will be limited and the knee will inevitably give way. To be stable a knee must have no 'lag ' in extension; the term 'lag' is used to mean that when the patient has actively straightened the knee, further passive extension is still possible.

\section{Technique}

A tourniquet is necessary, but, unless it is applied while the knee is held flexed, it will subsequently be difficult or impossible to pull the patellar tendon down sufficiently for adequate suture.

The operation itself is performed with the knee straight. A transverse incision is best, for the skin creases are transverse and the resulting scar is scarcely visible. If, however, the diagnosis is in doubt and it is not certain that patellectomy will prove necessary, a vertical para-patellar incision is used, for this gives better exposure of the joint.

The skin is reflected and the ligamentous fibres on the front of the patella are incised vertically and dissected off the bone. These fibres, which are firmly attached, must be meticulously scraped off with a sharp scalpel, so that not a scrap of soft tissue is left on the bone. One corner of the patella is then lifted up and dissected free. This corner is then held in strong forceps and pulled forwards so that the remainder of the bone may be shelled out, the knife always cutting as closc to the bone edge as possible. The interior of the joint and the femoral condyles are then inspected.

The deep layer of the extensor apparatus is repaired with mattress sutures of strong chromic

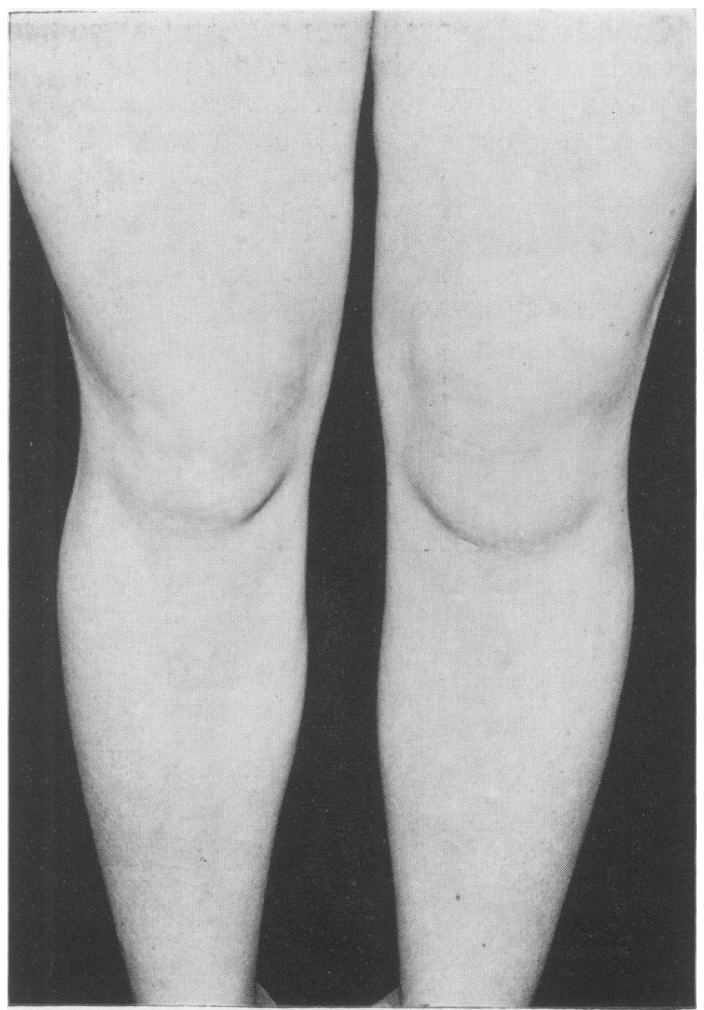

FIG. II.-Appearance of both knees after excision of the left patella.

catgut; these are best placed transversely, for vertical sutures tend to pull out. One or two additional oblique mattress sutures are inserted in such a way as to bunch up the tendon; the resulting lumpiness mimics the patella, and the subsequent appearance of the knee is almost normal (Fig. I I). The superficial fibres are then apposed with fine catgut, a few subcutaneous sutures are inserted and the skin is sewn up. A firm crepe bandage is applied over wool and the tourniquet removed. While the knee is held straight a padded plaster cylinder is applied from groin to malleoli. The anterior third of this plaster is removed and the remainder held firm with a bandage.

Five days later the cut edges of the plaster are eased apart and thereafter the plaster is used as a back splint. It is removed twice daily by a physiotherapist who teaches the patient exercises. Only gentle active extension is practised at first, and the knee must not be allowed to flex more than $30^{\circ}$ until the tendon has repaired, a process which takes six weeks.

Twelve days after operation the sutures are removed and as soon as the patient can lift the splinted leg off the bed she is allowed up. After 
six weeks the splint is left off at night and for periods during the day when the patient is not taking weight. Vigorous extension exercises are now practised and active flexion encouraged. The splint is not finally discarded until the patient has regained powerful quadriceps and has no trace of lag in extension.

\section{Acknowledgments}

I would like to thank Mr. G. Hadfield, F.R.C.S., for his help in preparing this article, and $\mathrm{Mr}$. $\mathrm{K}$.
Fensom of the Department of Clinical Photo-气̊ำ graphy for the illustrations.

\section{REFERENCES}

BROOKE, R. (1937), Brit. F. Surg., 24, 733.

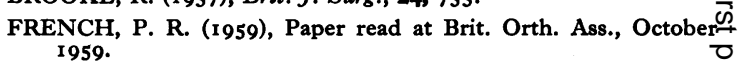

GRAY, C. (1948), Brit. med. F., i, 427.

KARLSON, S. (1939), Acta chir. scand., 83, 347.

MCFARLAND, B. (1948), $\mathcal{F}$. Bone $\mathscr{f}$ t. Surg., 30b, 58.

OWRE, A. (1936), Acta chir. scand., 77, Supp. 41.

SLOWICK, F. A. (1935), New Engl. F. Med., 213, 160.

\section{RENAL DISEASE}

(Postgraduate Medical Journal, November 1959)

Price 6s. 6d. post free

RECENT DEVELOPMENTS IN THE STUDY OF THE KIDNEY

A. A. G. Lewis, B.Sc., M.D., M.R.C.P.

RENAL BIOPSY AND

GLOMERULONEPHRITIS

J. H. Ross, M.D., M.R.C.P.

RECENT ADVANCES IN THE TREATMENT OF RENAL DISEASE

A. G. Spencer, M.D., M.R.C.P.

\section{HAEMODIALYSIS}

F. M. Parsons, B.Sc., M.B., Ch.B.

\section{DIURETICS}

H. G. Lloyd-Thomas, M.A., M.B., M.R.C.P.

\section{URINARY DIVERSION}

John Hopewell, F.R.C.S.

\section{RENAL ARTERY STENOSIS}

Kenneth Owen, M.S., F.R.C.S.

I. H. Griffiths, F.R.C.S.

Published by

THE FELLOWSHIP OF POSTGRADUATE MEDICINE

60, Portland Place, London, W.1 
secretion and therefore sodium conservation. Compensatory ADH secretion occurs, but may be insufficient to overcome this effect. In other words, most cases could be considered as examples of secondary aldosteronism.

Exceptions are to be found in cases of sodium loading, particularly in infants and those with poor renal function, and in some cases of adrenal steroid excess. However, in clinical practice even the former group often suffer some degree of dehydration.

The cause of the hypernatraemia associated with cerebral injuries is not finally decided in every case. In the majority it is due to deficient intake or excessive loss of water (diabetes insipidus, osmotic diuresis, sweating, overbreathing). It is also possible that brain damage may modify the function of the osmo-regulating and volumecontrolling mechanisms, leading directly to sodium retention and hypernatraemia.

\section{Acknowledgments}

My thanks are due to Dr. R. I. S. Bayliss and Dr. R. D. Tonkin for permission to include details of cases under their care.

\section{REFERENCES}

1. ALLOTT, E. N. (1939), Lancet, 1, ro35.

2. ANDERSON, C. H., MCCALLY, M., and FARRELL, G. L. (1959), Endocrinology, 64, 202.

3. BARTTER, F. C. (1956), Metabolism, 5, 369.

4. BARTTER, F. C., MILLS, I. H., BIGLIERI, E. G., and DELEA, C. S. (1959), Recent Progr. Hormone Res., 15, 31 r.

5. BERLINER, R. W., LEVINSKY, N. G., DAVIDSON, D. G., and EDEN, M. (i 958 ), Amer. F. Med., 24, 730.

6. BLACK, D. A. K., MCCANCE, R. A., and YOUNG, W. F. (1944), $\mathcal{F}$. Physiol., 102, 406.

7. CONWAY, E. J. (1947), Irish F. med. Sci., 262, 593.

8. COOPER, I. S., and CREVIER, P. H. (1952), f. clin. Endocr., I2, $82 \mathrm{I}$.

9. COOPER, I. S., and MACCARTY, C. S. (195I), Proc. Mayo Clin., 26, 354 .

10. DANÖWSKI, T. S., PETERS, J. H., RATHBUN, I. C., QUASHNOCK, J. M., and GREENMAN, L. (r949), $\mathcal{F}$. clin. Invest., 28, $\mathrm{r}$.

I r. DAVIS, J. O. (1959), Recent Progr. Hormone Res., 15, 298.

12. DEAN, R. B. (1941), Biol. Symposia, 3, 331.

13. DENTON, D. A., GODING, J. R., and WRIGHT, R. D. (1959), Brit. med. ., ii, 447.

14. DREIFUS, L. S., STAMLER, J., and LICHTON, I. J. (1959), Circulat. Res., 7, 314.

15. DUSTAN, H. P., CORCORAN, A. C., and PAGE, I. H. (1956), F. clin. Invest., 35, 1357 .

16. ENGSTROM, W. W., and LIEBMAN, A. (1953), Amer. $\mathcal{Y}$. Med., 15, 180 .

17. FARRELL, F. L., RAUSCHKOLB, E. W., and KOLETSKY, S. (1955), Ұ. clin. Endocr., 15, 852 .

18. FINBERG, L., and HARRISON, H. E. (1955), Pediatrics, I6, $\mathrm{I}$.
I8a. FOURMAN, P., and LEESON, PATRICIA M. (195. Lancet, i, 268.

19. GOLDSMITH, R. S., BARTTER, F. C., ROSCH, P. MERONEY, W. H., and HERNDON, E.'G. (1958), F. $d$ Endocr., 18, 323.

20. GOODALE, W. T., and KINNEY, T. D. (1949), Ann. inte Med., 31, 1 I 18 .

2r. GOWENLOCK, A. H., MILLS, J. N., and THOMAS, (1959), F. Physiol., 146, 133.

22. HARRISON, H. E., and FINBERG, L. (1959), Ped. clin. N. America, 6, 193.

23. HIGGINS, G., LEWIN, W., O'BRIEN, J. R. P., TAYLOR, W. H. (r95I), Lancet, i, I 295.

24. KNOWLES, H. C. (1956), Metabolism, 5, 508.

25. LEWIS, A. A. G. (1959), Postgrad. med. F., 35, 598.

26. LEWY, F. H., and GASSMANN, F. K. (1935), Amer. Physiol., 112, 504 .

27. LIDDLE, G. W., BARTTER, F. C., DUNCAN, L. BARBER, J. K., and DELEA, C. (1955), $\mathcal{F}$. clin. Inow 34, 949.

28. LIDDLE, G. W., DUNCAN, L. E., and BARTTER, F. (1956), Amer. F. Med., 21, 380.

29. LOCKWOOD, J. S., and RANDALL, H. T. (1949), BN N.Y. Acad. Med., 25, 228.

30. LUETSCHER, J. A., and AXELRAD, B. J. (1954), f. Endocr., 14, 1086.

31. LUETSCHER, J. A., and BLACKMAN, S. S. (1943), Ax intern. Med., 18, 74I.

32. McCANCE, R. A., and WIDDOWSON, E. M. (1957), Ac paediat. (Uppsala), 46, 337.

33. MACDONALD, W. B. (1955), Pediatrics, 15, 298.

34. MACFARLANE, A. (1926), $\mathcal{F}$. Pharmacol., 28, 177.

35. MALVIN, R. L., WILDE, W. S., VANDER, A. J., SULlivan, L. P. (1958), Amer. F. Physiol., 195, 549. ,

36. MILLS, I. H., CASPER, A., and BARTTER, F. C. (19q Science, 128, I1 40.

37. MYERS, G. B., and ISERI, L. T. (1955), Arch. intern. MC 95, 503 .

38. NATELSON, S., and ALEXANDER, M. O. (1955), Ibid 96, 172 .

39. PETERS, J. P. (1952), in 'Diseases of Metabolism,' by G. Duncan, Philadelphia, W. B. Saunders Co., p. 415.

40. PRUNTY, F. T. G., MCSWINEY, R. R., and MILLS, I. (1955), Proc. roy. Soc. Med., 48, 629.

41. RAPOPORT, S. (1947), Amer. F. Dis. Child., 74, 682.

42. REES, J. R., and ZILVA, J. F. (1959), f. clin. Path., 12, 561.

43. ROSS, E. J. (1959), 'Aldosterone in Clinical and Experiment Medicine,' Oxford: Blackwell, p. 80.

44. SCHOOLMAN, H. M., DUBIN, A., and HOFFMA W. S. (1955), Arch. intern. Med., 95, 15.

45. SMITH, H. W. (I95I), 'The Kidney,' Oxford Univeri' Press, p. 243.

46. STEVENSON, J. A. F., WELT, L. G., and ORLOFF, (1950), Amer. $\mathscr{F}$. Physiol., 161, 35.

47. VERNEY, E. B. (1946), Lancet, ii, 739 and 781 .

48. WARING, A. J., KAJDI, L., and TAPPAN, V. (1945), Am F. Dis. Child., 69, 323.

49. WELT, L. G., SELDIN, D. W., NELSON, W. P., GERMA W. J., and PETERS, J. P. (1952), Arch. intern. Med., 90, 35

50. WESSON, L. G., and ANSLOW, W. P. (1948), Amer. Physiol., 153, 465.

51. WESSON, L. G., and ANSLOW, W. P. (1952), Ibid., 170, 25 52. WINKLER, A. W., DANOWSKI, T. S., ELKINTOK J. R., and PETERS, J. P. (1944), F. clin. Invest., 23, $80 \%$.

53. YANKOPOULOS, N. A., DAVIS, J. O., KLIMAN, B., a PETERSON, R. E. (1959), Ibid., 38, 1278.

54. YOUNG, W. F., HALLUM, J. L., and MCCANCE, R. (1941), Arch. Dis. Child., 16, 243.

55. ZILVA, J. F., and HARRIS-JONES, J. N. (1957), f. clin. Path 10, 156. 